\title{
Error Analysis in Using Simple Past Tense Found in Students' Writing of Recount Text
}

\author{
Tira Nur Fitria \\ tiranurfitria@gmail.com \\ Sekolah Tinggi Ilmu Ekonomi AAS Surakarta
}

\begin{abstract}
This research was to find out the types of error analysis and the most dominant type of error analysis found in Students' Writing Composition in simple past tense especially in Recount Text. This study used a mixed-method, both qualitative and quantitative approach. From the analysis, the students' error in writing composition of simple past tense consists of some aspects of writing, they were in grammar, punctuation and spelling. In grammar, there were 57 data or $53.37 \%$, which consist of errors in class words like in determiner/article (25 data or $43.86 \%$ ), in verb (14 data or $24.56 \%$ ), in preposition (11 data or $19.30 \%$ ) and the last in noun (7 data or $12.28 \%$ ). While, the most dominant error was in the determiner/article. Second, in the aspect of spelling, there were 26 data or $21.70 \%$ ). Third, in the aspect of punctuation, there were (23 data or $24.53 \%$ ). Based on the frequency of each aspect of error, the most dominant error found in students' writing composition was in the aspect of grammar as 57 data or $53.37 \%$.
\end{abstract}

Copyright (C) 202x Institute of Advanced Engineering and Science. All rights reserved.

Keywords: Writing, simple past tense, Recount Text

\section{INTRODUCTION}

In education, English has been taught since the kindergarten level up to the university level, but in fact, there are still many people who cannot comprehend English well. In learning English, people must master four basic skills in English, namely listening, speaking, reading and writing. Listening and reading skill are the receptive skills because the learners/students do not need to produce a language, they receive and understand it. These skills are sometimes known as passive skills. While the productive skills are speaking and writing because the learners/students are applying these skills in a need to produce a language. They are also known as active skills.

The writing skill becomes the most complicated skill that should be mastered by the people, especially for the students because they should be able to combine and express their feelings or opinion into a well-written form. Writing is one of the language skills that should be acquired in learning the English language. Hasani (2005: 1) states that writing is the activity of a person in pouring ideas, thoughts, and feelings in a logical and systematic 
in written form, so that the message can be understood by the reader. Therefore, the main function of writing is as a means of communication indirectly. Writing means a process of communication that conveys ideas and opinions in a written form which suggests that the writers and the readers should have a similar understanding of what is written.

According to Harmer (2007: 258), the writing process is an interrelated set of recursive stages which include drafting, structuring, focusing, generating ideas and evaluating. Brown (2001: 335) states that written product is often the result of thinking, drafting and revising procedures that require specialized skill, a skill that not every speaker develop naturally. In short, writing is a product bypassing the process of thinking the ideas (planning), drafting, revising, evaluation (editing) until the final draft.

Writing English has rules, which can make it a difficult language to be learned. Some of the areas in particular that language-learners struggle with our grammar, punctuation and spelling. Grammar is an important part of writing. Besides that, punctuation and spelling also important in writing because there are language components in writing English well. These cannot be separated from each other because there are related to another component.

In fact, writing in English is not easy for some learners/students. They may have difficulties when they use the language in writing. Because of this, there will be errors that can be found in their writing. Perhaps, the students have many problems in writing English then cause an error in writing product. While actually, making errors, students will build their new knowledge to use the target language as Selinker (Mei Lin Ho, 2003: 1) states, making errors during learning the second language can be considered as a mean of building students' abilities because they can learn something from making errors.

In linguistics, according to Richard et al., (2002: 184), an error is the use of a word, speech act or grammatical items in such a way it seems imperfect and significant of incomplete learning. While error analysis is a method used to document the errors that appear in learner language, determine whether those errors are systematic, and (if possible) explain what caused them. The errors can occur in writing paragraphs or composition by using tense because tenses are needed in English texts. Sometimes students still confuse how to use tense in writing a sentence. Errors are signs from the students who have not mastered the English rules (Fitria, 2019). Errors usually committed by the second of foreign language learners are an inevitable part of language learning. Through making errors, and hearing the correct forms from the teacher, the learners can develop their skills. So, errors and their analysis are advantageous for both learners and teachers. 
According to Cowan (2008), the simple past tense is used for activities or situations that began and ended in the past. In simple past tense, the students usually write recount text and have to know simple past tense well. According to Anderson and Anderson (2003: 24), recount text is a piece of text that retells past events, usually in the order in which they occurred. Ellis (1997: 7) states that the student will do the same error several times until they know about the correct one from another resource that can prove their errors in writing English.

There is previous research that is related to error analysis. Research is written by Fitria (2018) entitled Error Analysis Found in Students' Writing Composition of Simple Future Tense. That research found the kind of error analysis found in students' writing composition in the aspects of grammar, punctuation, and spelling, and to find the most dominant kind of error analysis found in students' writing composition of the simple future tense. The result of the analysis shows that the students' error in writing composition of simple future tense consists of three aspects of writing. First, in grammar, punctuation, and spelling. In grammar aspect, there are errors in some points of class word like in noun (21 data or 36, $84 \%$ ), determiner/article ( 2 data or $3,51 \%$ ), pronoun ( 1 data or $1,75 \%$ ), preposition (15 data or $26,32 \%$ ) and verb (18 data or $31,58 \%$ ), then the most dominant error in grammar aspect is noun. Second, in punctuation (16 data or 17, 20\%). Third, in spelling (20 data or $21,51 \%)$. Based on the frequency of each aspect of error writing shows that the most dominant error found in the students' writing composition is in the aspect of grammar as 57 data or $61,29$.

Based on the explanation above, the writer is interested in conducting the same study about error analysis, but different data of the research entitled "An Error Analysis Found in Students' Writing Composition of simple past tense". This research will find out the types of error analysis found in the Students' Writing Composition in the aspect of grammar, punctuation, and spelling and to find out the most dominant kind of error analysis found in Students' Writing Composition in simple past tense.

\section{RESEARCH METHOD}

The design used in this study is a qualitative and quantitative approach. In qualitative, the writer used descriptive design because the data obtained is information that focuses on current status and phenomena. In conducting this study, the writer 
considers that the descriptive method is a suitable method. In gathering data, it can be statistically computed, so the quantitative approach is a way to analyze the numeric data.

Arikunto (2006:12) states that a quantitative approach is an approach that demands to use the numeric, begin from the collection of the data, interpretation of data, presentation of the data and also the result. On the other hand, to make an understandable study, the writer should use a quantitative approach if the data is gathered in the form of numeric, graphic, table or percentage.

The object of the research is 19 students' writing composition which was taken from 15 Diploma students of D3 STIE AAS Surakarta. The students' writing composition means the result of the student's composition in writing simple past tense, especially in recount text.

In collecting the data, the writer uses documentation. The documentation method related to all of the documents. It can be a textbook, newspaper, letter, piece of paper, email, etc. For this study, the writer analyzes the students' writing in recount text as the data. Furthermore, the writer analyzed the document to find the error made by the students in their writing of recount text.

Ellis (1994:57- 68) stated that steps to analyze the errors are the identification of error, classification of error, description of the error, explanation of the error then tabulation. The data were finally tabulated to know the frequency of errors that are made by the students. The description is as follows.

1. Identification of errors

The first step in the process of analysis is the identification of the errors. In this step, the writer identifies the students' errors in their writing of recount text includes the use of a proper noun, descriptive words, simple past tense, and the time connective.

2. Classification of error

In this step, the errors are classified into some categories. Besides that, describing the error is to identify the differences of disordering of word between students' utterances and the reconstruction of target language utterances.

3. Explanation of errors

In this step, the writer will explain the source of an error made by the students. The writer tries to figure out the source of error by predicting it.

4. Tabulation of errors 
In this step, the writer draws the error into a table based on the classification of errors to tabulate the number of errors made by the students and then figures out the most dominant errors in the student writing.

\section{RESULTS AND ANALYSIS}

\section{Results}

The findings of this research are to answer the research objectives as formulated in the background of the study. This research will find out the kind of error analysis found on students' writing composition in the linguistic aspects of grammar, punctuation, and spelling and to find out the most dominant kind of error analysis found in students' writing composition of simple past tense. Below the error analysis and their description of the data research as follow:

\section{a. Grammar}

Harmer (2001:12) defines grammar as the description of the ways in which words can change their forms and can be combined into sentences in that language. Brown said (2000:362) that grammar is the system of rules governing the conventional arrangement and relationship of words in a sentence. Without grammar we cannot make a good language and the language we produce will not be understood by others. Therefore, grammar is the important part of language that can make the language clearly or unclearly understood. Errors in grammar usually happen because the writer does not understand how to use punctuation marks. Below the errors which is found in students' writing composition, as follow:

\section{b. Determiner/Article}

In the example of the fourth students' writing composition

Wrong : This is my activity when holiday yesterday.

Correct: This is my activity on the last holiday.

The example above shows that there is an error in the aspect of grammar especially in determiner/article. In that sentence, it appears that an article is missing before the word "holiday". It is considered in adding an article "a" or "the". Therefore, it will be "a holiday" or "the holiday".

In the example of the eighth students' writing composition

Wrong : We also took the time buy souvenir.

Correct: We also took the time to buy a souvenir/the souvenir. 
The example above shows that there is an error in the aspect of grammar especially in determiner/article. In that sentence, it appears that an article is missing before the word "holiday". It is considered in adding an article "a" or "the". Therefore, it will be "a souvenir" or "the souvenir".

In the example of the ninth students' writing composition

Wrong : It was a best holiday.

Correct: It was the best holiday.

The example above shows that there is an error in the aspect of grammar especially in determiner/article. In that sentence, it appears that the phrase "a best" does not contain the correct article usage. It is considered in changing an article "the". Therefore, it will be "the best".

In the example of the eleventh students' writing composition

Wrong : Therefore, we wanted to go to city.

Correct: Therefore, we wanted to go to a city/the city.

The example above shows that there is an error in the aspect of grammar especially in determiner/article. In that sentence, it appears that an article is missing before the word "holiday". It is considered in adding an article "a" or "the". Therefore, it will be "a city" or "the city".

In the example of the thirteen students' writing composition Wrong : Last holiday in new year, my family and I went to...

Correct: Last holiday in a new year/the new year, my family and I went to...

The example above shows that there is an error in the aspect of grammar especially in determiner/article. In that sentence, it appears that the phrase "a best" does not contain the correct article usage. It is considered in changing an article "a" or "the". Therefore, it will be "a new year" or "the new year".

\section{c. Verb}

In the example of the fourth students' writing composition

Wrong :... what should I do to filled my holiday

Correct:... what should I do to fill my holiday

The example above shows that there is an error in the aspect of grammar especially in part of speech in the verb. The to-infinitive that follows the verb "filled" requires the base form. It is considered in changing the word "filled" into the base form or verb 1 "fill". 
ADJES

In the example of the fourth students' writing composition

Wrong : ...until I didn't realized, time for pray Dzuhur was arrived.

Correct: ...until I didn't realize, time for praying Dzuhur arrived.

The example above shows that there is an error in the aspect of grammar especially in part of speech in the verb. In the sentence above, it appears that the verb "realized" is incorrectly used with the helping verb of past "did". It is considered in changing it to the base form. Therefore, it should be "realize".

In the example of the fourth students' writing composition

Wrong : ...time for pray Dzuhur was arrived...

Correct : ...time for praying Dzuhur arrived/has arrived...

The example above shows that there is an error in the aspect of grammar especially in part of speech in the verb. In the sentence above, it uses the transitive verb "arrived" in a passive voice construction. It is considered in writing the sentence in the active sentene. Therefore, it should be "arrived" or "has arrived".

In the example of the twelve students' writing composition

Wrong : ...so many people came to Parangtritis to spent their time.

Correct: ...so many people came to Parangtritis to spend their time.

The example above shows that there is an error in the aspect of grammar especially in part of speech in the verb. In the sentence above, it appears that the verb "spent" should be in the base form as part of the to-infinitive following the word "came". It is considered in changing the word into Verb 1 "spend".

In the example of the fourteen students' writing composition

Wrong : After that, we went to the tourist spot which become a favourite place

Correct: After that, we went to the tourist spot which becomes a favourite place

The example above shows that there is an error in the aspect of grammar especially in part of speech in the verb. In the sentence above, the plural verb "become" does not appear to agree with the singular subject "the tourist spot". It is considered in changing the verb form for subject-verb agreement. Therefore, it should be "becomes".

In the example of the fifteen students' writing composition

Wrong : ...we played in the beach, we decided to went home soon.

Correct: ...we played on the beach, we decided to go home soon. 
The example above shows that there is an error in the aspect of grammar especially in part of speech in the verb. In the sentence above, it appears that the verb "went" should be written in the base form as part of the to-infinitive following "decided". It is considered in changing the verb form. Therefore, it should be "go".

\section{d. Preposition}

In the example of the fourth students' writing composition

Wrong : ...for young people specially for their problem about love.

Correct: ...for young people specially for their problem with love.

The example above shows that there is an error in the aspect of grammar especially in grammar especially part of speech in preposition. In that sentence, it appears that the preposition "about" may be incorrect in this context. It is considered in changing an appropriate preposition "with".

In the example of the sixth students' writing composition

Wrong : At 2 pm I went to home but before I went to home,

Correct: At 2 pm I went to home but before I went to home,

The example above shows that there is an error in the aspect of grammar especially in grammar especially part of speech in preposition. In that sentence, the preposition "to" seems unnecessary written after the verb "went" It is considered in removing an appropriate preposition "to".

In the example of the eighth students' writing composition

Wrong : We went on the 2nd trip in cave Gong.

Correct: We went to the 2nd trip in cave Gong.

The example above shows that there is an error in the aspect of grammar especially in grammar especially part of speech in preposition. In that sentence, it appears that the preposition "in" may be incorrect in this context. It is considered in changing an appropriate preposition "to".

In the example of the eighth students' writing composition

Wrong : Around at 14.00, we arrived in our second destination.

Correct: At around 14.00, we arrived at our second destination.

The example above shows that there is an error in the aspect of grammar especially in grammar especially part of speech in preposition. It that sentence, it appears that the 
preposition "in" may be incorrect in this context. It is considered in changing an appropriate preposition "at".

In the example of the seventeen students' writing composition

Wrong : At 14th January 2018 we did that plan.

Correct: On 14th January 2018 we did that plan.

The example above shows that there is an error in the aspect of grammar especially in grammar especially part of speech in preposition. In that sentence, it appears that the preposition "at" may be incorrect in this context. It is considered in changing an appropriate preposition "on".

\section{e. Noun}

In the example of the first students' writing composition

Wrong : ..., we saw many beautiful view such as rice fields, mountains, etc.

Correct: ..., we saw many beautiful views such as rice fields, mountains, etc.

The example above shows that there is an error in the aspect of grammar especially in part of speech in nouns. The singular countable noun "view" follows the quantifier "many", which requires a plural noun. It is considered using a plural noun or a different quantifier. Therefore, it should be changed into appropriate plural noun "views".

In the example of the fifth students' writing composition

Wrong : It turns out the voice is my brother voice.

Correct: It turns out the voice is my brother's voice.

The example above shows that there is an error in the aspect of grammar especially in part of speech in nouns. In the sentence above, it appears that the noun "brother" should be in the possessive form. It is considered in changing the noun form. Therefore, it should be "brother's".

In the example of twelve students' writing composition

Wrong : After three hour rode my car,...

Correct: After three hours driving my car,...

The example above shows that there is an error in the aspect of grammar especially in part of speech in nouns. The singular noun "hour" follows a number other than one. It is considered in changing the noun to the plural noun "hours".

In the example of the sixteen students' writing composition 
Wrong : ...but we have little problems, $\ldots$

Correct: ....but we have little problem, ...

The example above shows that there is an error in the aspect of grammar especially in part of speech in nouns. In the sentence above, the definitive article "a" may not be required with the plural noun "problems". It is considered in changing the noun to singular. Therefore, it should be "problem".

In the example of the eighteen students' writing composition

Wrong : ...there are still many guest who arrive.

Correct: ...there are still many guests who arrive.

The example above shows that there is an error in the aspect of grammar especially in part of speech in nouns. In the sentence above, the singular countable noun "guest" follows the quantifier "many", which requires a plural noun. It is considered in using a plural noun. Therefore, it should be "guests".

\section{f. Spelling}

Spelling is related with the pronunciation of certain arrangements of letters. Spelling, the art of correctly assembling words from their letters, is one of the essential components of successful writing. Errors in spelling usually happen because the writer does not understand how to spell the words correctly. Below some errors which is found in students' writing composition, as follow:

In the example of the second students' writing composition

Wrong : ..., so we went to a chinnese restaurant.

Correct: ..., so we went to a Chinese restaurant.

The example above shows that there is an error in the aspect of grammar especially in spelling. In that context, the word "chinnese" is not in the dictionary or miswritten. It is considered in changing an appropriate word. Therefore, it should be "Chinese".

In the example of students' writing composition

Wrong : because so colourfully decorated by fireworks.

Correct: because it is so colorfully decorated by fireworks.

The example above shows that there is an error in the aspect of grammar especially in spelling. In that context, the spelling of "colourfully" is a non-American variant. For consistency, it is considered replacing it with the American English spelling. Therefore, it should be "colorfully". 
In the example of the third students' writing composition

Wrong : I wanted to have a lot of time hangout with my family at home.

Correct: I wanted to have a lot of time to hang out with my family at home.

The example above shows that there is an error in the aspect of grammar especially in spelling. The word "hangout" may be used incorrectly. It is considered to determine the appropriate usage for this context. The word "hangout" should be added a space between the word "hang" and "out".

In the example of the fourth students' writing composition

Wrong : ...for young people specially for their problem about love.

Correct: ...for young people especially for their problem with love.

The example above shows that there is an error in the aspect of grammar especially in spelling. In that context, the word "specially" may be used incorrectly. It is considered to determine an appropriate usage for this context. Therefore, it should be "especially".

In the example of the seventh students' writing composition

Wrong : ....because can not see the sun rise.

Correct: ....because I cannot see the sunrise.

The example above shows that there is an error in the aspect of grammar especially in spelling. In the sentence above, the word "can not" seems to be miswritten. It is considered in replacing it or changing it into an appropriate writing by deleting a space. Therefore, it should be "cannot". While, in the word "sun rise" seems to be miswritten. It is considered in replacing it or changing it into an appropriate writing by deleting a space. Therefore, it should be "sunrise".

In the example of fourteen students' writing composition Wrong : ...we went to the tourist spot which become a favourite place in Jogja,... Correct: ....we went to the tourist spot which has become a favorite place in Jogja,...

The example above shows that there is an error in the aspect of grammar especially in spelling. In that context, the spelling of "favourite" is a non-American variant. For consistency, it is considered replacing it with the American English spelling. Therefore, it should be "favorite".

\section{g. Punctuation}

Punctuation is a symbol used to create sense, clarity, and stress in sentences. You use punctuation marks to structure and organize your writing. Punctuation shows how the 
sentence should be read and makes the meaning clear, so without punctuation writing becomes hard to read. Punctuation is very important because it helps the readers to make sense of a piece of text. Errors in punctuation usually happen because the writer does not understand how to use punctuation marks. Below the errors which are found in students' writing composition, as follow:

In the example of the first students' writing composition

Wrong : Finally we decided to go home at $06.00 \mathrm{pm}$ on that day.

Correct: Finally, we decided to go home at $06.00 \mathrm{pm}$ on that day.

The example above shows that there is an error in the aspect of punctuation. In that sentence, it appears that there is missing a comma after the introductory phrase "Finally". It is considered adding a comma. Therefore, it should be "Finally,...".

In the example of the second students' writing composition

Wrong : After that we went to Gembira Loka zoo.

Correct: After that, we went to Gembira Loka zoo.

The example above shows that there is an error in the aspect of grammar especially in punctuation. In that sentence, it appears that there is missing a comma after the introductory phrase "That". It is considered adding a comma. Therefore, it should be "After that,...".

In the example of the eighth students' writing composition

Wrong : On the beach we can not just swim the beach or play water and sand.

Correct: On the beach, we can not just swim on the beach or play water and sand.

The example above shows that there is an error in the aspect of grammar especially in punctuation. In that sentence, it appears that there is missing a comma after the introductory phrase "On the beach". It is considered adding a comma. Therefore, it should be "On the beach,...".

In the example of the fourteen students' writing composition

Wrong : In his house we chatted jokingly.

Correct: In his house, we chatted jokingly.

The example above shows that there is an error in the aspect of grammar especially in punctuation. In that sentence, it appears that there is missing a comma after the introductory phrase "In his house". It is considered adding a comma. Therefore, it should be "In his house,...".

ADJES Vol.7, No. 1, March 2020 : 39-54 
ADJES

In the example of the sixteen students' writing composition

Wrong : On the night day the weather was very bad.

Correct: On the night day, the weather was very bad.

The example above shows that there is an error in the aspect of grammar especially in that sentence, it appears that there is missing a comma after the introductory phrase "On the night day". It is considered adding a comma.

In the example of the seventeen students' writing composition

Wrong : We would go to Bandungan together, because we need holiday.

Correct: We would go to Bandungan together because we need a holiday.

The example above shows that there is an error in the aspect of grammar especially in punctuation. In this context, it appears that there is an unnecessary comma after the dependent clause marker "because". It is considered in removing the comma after the word "because".

\section{Discussion}

Error Analysis (EA) is simply the systematic study of language mistakes. This analysis is done so that the identified errors can be systematically learned from and weeded out. Error analysis is also a useful device in knowing the progress of the learner toward the foreign language. Error analysis provides a deep insight into the understanding of the process of language learning. It helps teachers in understanding the new ways of teaching by giving feedback on the errors made by the learners. It is certain and understood that learners make mistakes in the process of learning. These mistakes provide new insights and techniques to the language teachers and linguists in sorting out the problems related to language learning.

This research will find out the kind of error analysis in the aspect of grammar, punctuation, and spelling and to find out the most dominant kind of error analysis found in Students' Writing Composition of Simple Future Tense. Below the table of the result of students' writing composition, it is found of errors in the aspect of grammar, punctuation, and spelling:

Table 3.1. Frequency of Error in Students' Writing Composition

\begin{tabular}{|c|c|c|c|c|c|c|}
\hline \multirow{3}{*}{ ASPECT } & \multicolumn{4}{|c|}{ Grammar } & \multirow[b]{2}{*}{ Spelling } & \multirow[b]{2}{*}{ Punctuation } \\
\hline & $\begin{array}{c}\text { Determiner/ } \\
\text { Article }\end{array}$ & Verb & Preposition & Noun & & \\
\hline & $\begin{array}{c}25 \\
43.86 \% \\
\end{array}$ & $\begin{array}{c}14 \\
24.56 \%\end{array}$ & $\begin{array}{c}11 \\
19.30 \%\end{array}$ & $\begin{array}{c}7 \\
12.28 \%\end{array}$ & 26 & 23 \\
\hline TOTAL & \multicolumn{4}{|c|}{57} & \multirow[b]{2}{*}{$21.70 \%$} & \multirow[b]{2}{*}{$24.53 \%$} \\
\hline$\%$ & & & $37 \%$ & & & \\
\hline
\end{tabular}

Error Analysis Found in Students' Writing Composition in simple past tense "Recount Text" (Tira 
From the table above, it shows that the students' error in writing composition of simple present tense consists of three aspects of writing, namely in grammar, punctuation, and spelling. First, in the aspect of grammar, there are 57 data or $53.37 \%$, which is consisted of errors in some points of class word like in determiner/article ( 25 data or 43.86 $\%$ ), in verb (14 data or $24.56 \%$ ), in preposition (11 data or $19.30 \%$ ) and the last in noun (7 data or $12.28 \%$ ). While the most dominant error was found in the determiner/article. Second, in the aspect of spelling, there are 26 data or $21.70 \%)$. Third, in the aspect of punctuation, there is ( 23 data or $24.53 \%$ ). Based on the frequency of each aspect of error writing shows that the most dominant error found in the students' writing composition is in the aspect of grammar as 57 data or $53.37 \%$. Below the analysis and description of the students' error in writing composition of simple past tense consist of three aspects of writing, as follows:

First, in the grammar aspect. The grammar aspect is the first rank of the error analysis type found in students' writing composition of simple past tense. In this research, there are some errors in class words (part of speech) such as in determiner/article, verb, preposition, and noun. In verbs, the students have many errors in writing. In the determiner/article, there are some errors such as 1) Missing article before certain words. 2) Writing incorrect article usage follows a certain phrase in the sentence. Both two errors, it is considered in adding an article "a" or "the". In verb, there are some errors such as 1) Writing to-infinitive. Some words do not follow the rule, which certain verb requires the base form. 2) Writing a helping verb. Some words are incorrectly written. Both two errors, it is considered in changing certain words into the base form of verb 1. 3) Writing transitive verb. There is a word written in a passive construction. Therefore, it is considered in writing the sentence in the active sentence, and 4) Writing incorrect subject-verb agreement. There is a word incorrectly written. The plural verb does not appear to agree with the singular subject. Therefore, it is considered in changing the verb. In preposition, there are some errors such as in some examples appears that the preposition may be incorrect in those contexts. Therefore, it is considered in changing an appropriate preposition. While, in nouns, there are some errors such as 1) Writing inappropriate singular and plural nouns. The singular countable noun follows the quantifier "many" which requires a plural noun, and the definitive article "a" may not be required with the plural noun. 2) Writing possessive forms of the noun. In the example, a sentence appears that the noun should be in the possessive form. It is considered in changing the noun form. 
Second, in the spelling aspect. The spelling aspect is the second rank of the error analysis type found in students' writing composition of simple past tense. In this research, there are some errors, such as in 1) Writing inappropriate words. In the example shown, some words are not found in the dictionary or miswritten. Therefore, it is considered in changing an appropriate word or an appropriate usage in this context. 2) Writing nonAmerican variants. The spelling of some words is a non-American variant. For consistency, it is considered replacing it with the American English spelling.

Third, in the punctuation aspect. The punctuation aspect is the third rank of the error analysis type found in students' writing composition of simple past tense. Missing a comma after the introductory phrases. In the examples, the sentences appear that there are missing a comma after the introductory phrase "Finally", "After that" etc. Therefore, it is considered adding a comma after it. 2) Missing a comma after the dependent clause marker. In the examples, the sentences appear that there is an unnecessary comma after the dependent clause marker "because". It is considered in removing the comma after the word "because".

\section{CONCLUSION}

From the analysis of this research, it is found that the students' error in writing composition of simple past tense in recount text consists of three aspects of writing, they are in grammar, punctuation, and spelling. First, in the aspect of grammar, there are 57 data or $53.37 \%$, which is consisted of errors in some points of class word like in determiner/article ( 25 data or $43.86 \%$ ), in verb (14 data or $24.56 \%$ ), in preposition (11 data or $19.30 \%$ ) and the last in noun (7 data or $12.28 \%$ ). While the most dominant error was found in the determiner/article. Second, in the aspect of spelling, there are 26 data or $21.70 \%$ ). Third, in the aspect of punctuation, there is (23 data or $24.53 \%$ ). Based on the frequency of each aspect of error writing shows that the most dominant error found in the students' writing composition is in the aspect of grammar as 57 data or $53.37 \%$.

\section{REFERENCES}

Anderson, Mark and Kathy Anderson. (2003). Text Type in English 3. Australia: Macmilan Education Australia PTYLTD.

Azar, Betty Schramper. (2002). Understanding Using English Grammar. USA: Englewood Cliffs Prentic Hall. 
Brown, H. D. (2000). Principles of Language Learning and Teaching. Longman.

Brown, H. Douglas. (2001). Principles of Language and Teaching Fourth Edition. San Francisco: Addison Wesley Longman, Inc.

Cowan, R. (2008). The teacher's Grammar of English. Cambridge: Cambridge University.

Djuharie, Otong Setiawan. (2007). Genre Dilengkapi 700 Soal Uji Kepahaman. Bandung: CV. Yrama Widya

Ellis, Rod. (1997). Second Language Acquisition. New York: Oxford University Press.

Fitria, T. N. (2018). Error Analysis Found in Students' Writing Composition of Simple Future Tense. ELS Journal on Interdisciplinary Studies in Humanities, 1(3), 240-251.

Fitria, T. N. (2019). Errors In Students'writing Composition In Simple Present Tense "My Daily Activity". Edulangue, 2(1), 47-62.

Harmer, Jeremy. (2007). The Practice of English Language Teaching. Cambridge: Longman.

Hasani, A. (2005). Ihwal Menulis. Serang: Untirta Pers.

Hayland, Ken. (2003). Second Language Writing. New York: Cambridge University Press.

Richards, J. C. \& Schmidt, R. (2002). Dictionary of Language Teaching and Applied Linguistics (3rd Ed.). London: Longman.

Uchiyama, K. (2006). English Verb Tenses: An Informal But Extensive Reference For ESL Students, the Good Folks Who Teach Them, the Idly Curious, and the Linguistically Perplexed. San Francisco: Chabot College. 